\title{
Spatial relationships between diffuse prion protein deposits and neuronal perikarya in variant Creutzfeldt-Jakob disease
}

\author{
Richard A. Armstrong \\ Vision Sciences, Aston University, Birmingham, UK
}

\begin{abstract}
Two morphological types of prion protein (PrPsc) deposit occur in the cerebral cortex of cases of variant CreutzfeldtJakob disease (VCJD), viz., diffuse and florid deposits. The objective of this study was to determine whether diffusetype PrPsc deposits in areas of the cerebral cortex in six cases of the variant form of CJD (VCJD) were spatially correlated with neurons and whether diffuse deposit size was related to the number of adjacent neurons contributing PrPsc. In cortical gyri, density of surviving neurons was 5.38-12.15 per $50 \times 200 \mu \mathrm{m}$ sample field, neurons being distributed randomly, regularly or were clustered relative to the pia mater. Density of neurons embedded within diffuse deposits, however, was three to eight times their overall density in the section. In addition, diffuse deposit area was positively correlated with the number of embedded neurons. The frequency distribution of diffuse deposits with $0,1,2,3, \ldots, n$, embedded neurons did not deviate from a Poisson distribution. These results suggest: (1) diffuse deposits in vCJD develop in situ as a result of the formation of PrPsc in relation to clusters of neurons, (2) size of a diffuse deposit is determined by the number of adjacent neurons which develop PrPsc, and (3) the probability that PrPsc is formed in relation to one neuron is independent of that of its neighbour.
\end{abstract}

Key words: variant Creutzfeldt-Jakob disease (VCJD), diffuse prion protein (PrP) aggregates, neuronal perikarya, Poisson distribution, size distribution.

\section{Introduction}

Variant Creutzfeldt-Jakob disease (vCJD), a new subtype of CJD, was first described in the UK in 1996 [22,39]. The majority of patients initially develop psychiatric symptoms such as depression and/or anxiety, followed by ataxia, involuntary movements, and cognitive impairments. Most patients affected to date are young (median age 28 years, range 14-74 years) and death occurs within 12-24 months [39].

Neuropathologically, VCJD is characterised by the deposition in the brain of the disease form of prion protein (PrPsc) as discrete aggregates or deposits [10,19, 20,22,28,29,31]. The PrPsc characteristic of vCJD has a uniform glycotype (PrPsc, Type 4) and is distinct from that observed in sporadic CJD (SCJD) [18,21]. Two morphological types of PrPsc deposit are commonly observed in VCJD $[10,15]$. First, florid deposits [27] comprise a condensed core of PrPsc and are heavily stained with antibodies raised against PrP. Second, diffuse deposits (also known as 'fine feathery diffuse deposits' or 'fine diffuse deposits') are more lightly stained, irregular in shape, and lack a solid PrPsc core. 
Different pathological processes are likely to be involved in the formation of the diffuse and florid deposits [10].

A nucleation-dependent mechanism is involved in the formation of PrPsc deposits in CJD with conformational transition from a soluble protein $(\mathrm{PrPc})$ to a protease resistant $\beta$-sheet with neurotoxic properties $[21,26,28,29]$. The mechanism of this conversion is unknown but it depends on various factors including $\mathrm{pH}$ [38], oxidation of $\mathrm{PrPc}^{\mathrm{c}}$ [40], the presence of glycosaminoglycans [30], while non-coding RNA may act as a catalyst [16]. In addition, several regions of PrPc may play a role in PrPsc formation. For example, animal transgenic studies in mice and biochemical data suggest residues 100-104 are critical for binding of PrPc to PrPsc and essential for prion propagation $[17,36]$ whereas in humans, residues 138-141 is essential [25]. $\mathrm{PrPc}$ has been shown to be present on cell membranes within PrP deposits [23], is enriched in caveolae and may be delivered via caveolae to late endosomes/lysosomes, bypassing the internalisation pathway mediated by clathrin-coated vesicles [33].

Subsequently, two stages in the formation of a PrPsc deposit can be identified. First, initiation of the deposit (nucleation) in which PrPc is converted in the presence of PrPsc into $\beta$-sheets and second, the growth and further development of the $\beta$-sheets into discrete deposits. Two further processes are then involved in the development of the deposits. First, formation and removal of PrPsc molecules (aggregation/disaggregation) and second, diffusion of substances, including molecular chaperones, into the developing deposits (surface diffusion) [35]. During aggregation, each particle of PrPsc has a probability of associating with a new particle of PrPc causing its conversion to PrPsc and resulting in growth of the deposit. During dis- aggregation, $\mathrm{PrPs}^{\mathrm{sc}}$ molecules may be randomly removed from the deposit by glial cells [10] resulting in the shrinkage and even clearance of a deposit. By contrast, surface diffusion describes a process by which additional molecular constituents bind to existing proteins, thus influencing their growth and morphology [37].

Diffuse deposits, 10-200 $\mu \mathrm{m}$ in diameter, have been recorded in the cerebral cortex in VCJD [12]. The size frequency distribution of these deposits is unimodal and positively skewed [12], i.e. there are few deposits in the smallest $(<10 \mu \mathrm{m})$ size class, maximum frequency occurs between $20 \mu \mathrm{m}$ and $40 \mu \mathrm{m}$ (the modal class), and the frequency of the larger deposits declines with increasing size. Diffuse deposits $<50 \mu \mathrm{m}$ in diameter often contain a single surviving neuronal perikaryon while those $>50 \mu \mathrm{m}$ may contain up to 2 to 3 cell bodies [10]. These observations suggest that diffuse deposits may develop as a result of the formation of PrPsc in relation to clusters of neurons, the size of a deposit being determined by the number of neurons in the cluster involved. To test this hypothesis: (1) the density and spatial patterns of surviving neuronal perikarya were studied in the cerebral cortex in VCJD, (2) the density of neuronal perikarya embedded within diffuse deposits was compared to that of the section as a whole, (3) the correlation between diffuse deposit area and number of embedded neurons was tested, and (4) the frequency distribution of diffuse deposits containing $0,1,2,3, \ldots, n$, embedded neuronal perikarya was tested against a random (Poisson) distribution.

\section{Material and methods \\ Cases}

Six cases of VCJD (details in Table I) were studied at the Department of Neuropathology, Institute of Psy-

Table I. Demographic features, gross brain weight, and degree of atrophy of the variant Creutzfeldt-Jakob disease (VCJD) cases studied

\begin{tabular}{|lccccc|}
\hline Case & Sex & Age at onset (yrs) & Duration (yrs) & Brain weight (gm) & Atrophy \\
\hline A & F & 39 & 2 & $586 \mathrm{~L}$ & None \\
\hline B & F & 28 & 1 & 1375 & None \\
\hline C & F & 28 & 1 & NA & NA \\
\hline D & M & 19 & 1 & NA & NA \\
\hline E & M & 30 & 1 & $699 R$ & None \\
\hline F & M & 48 & 2 & 1470 & None \\
\hline
\end{tabular}

$M$ - male, F-female, $R$-right hemisphere only, $L$ - left hemisphere only, $N A$ - data not available 
chiatry, King's College London, UK. Brain material was obtained from the National CJD Surveillance Unit, Western General Hospital, Edinburgh, UK. The principles embodied in the 1975 Helsinki declaration (as modified Edinburgh, 2000) were followed with respect to experiments involving material of human origin. All cases fulfilled the criteria for a pathological diagnosis of vCJD $[19,21,22]$. None of the cases had any of the known mutations of the PrP gene or family history of prion disease, and there was no evidence of the known types of iatrogenic aetiology. The pattern of PrPsc deposition typical of VCJD was observed in all cases with florid and diffuse-type deposits in the cerebral cortex, cerebellum, basal ganglia, thalamus, and brain stem [20,22].

\section{Preparation of material}

Blocks of frontal cortex (B8) at the level of the genu of the corpus callosum, parietal cortex (B7) at the level of the splenium of the corpus callosum, occipital cortex including the calcarine sulcus (B17), and temporal cortex at the level of the lateral geniculate body to study the parahippocampal gyrus (B28), were taken from each case. Tissue was fixed in $10 \%$ phosphate buffered formal-saline and embedded in paraffin wax. Coronal $7 \mu \mathrm{m}$ sections were immunolabelled against PrP using the monoclonal antibody $12 \mathrm{~F} 10$ (dilution 1 : 250) that binds to residues 142-160 of human PrP downstream of the neurotoxic domain adjacent to helix region 2 [24] (kindly provided by Prof. G. Hunsmann, The German Primate Centre, Gottingen, Germany). Immunoreactivity was enhanced by formic acid ( $98 \%$ for 5 minutes) and autoclaving $\left(121^{\circ} \mathrm{C}\right.$ for 10 minutes) pretreatment. Sections were treated with Dako Biotinylated Rabbit antiMouse (RAM) (dilution 1 : 100) and Dako ABComplex HRP kit for 45 minutes (Amersham, UK). Diaminobenzidine tetrahydrochloride was used as the chromogen. Immunolabelled sections were also stained with haematoxylin for 1 minute.

\section{Spatial pattern of surviving neurons}

The spatial pattern of surviving neuronal cell perikarya was studied in each cortical gyrus along strips of cortex oriented parallel to the pia mater. Guidelines were marked on the slide to sample neuronal perikarya located approximately in laminae II/III and IV/V. The number of surviving neuronal cell bodies within each sample field was counted at a magnification of $\times 400$ in $250 \times 50 \mu \mathrm{m}$ contiguous sample fields, the upper edge of the sample field being aligned with the appropriate guideline. Neurons were identified as cells containing at least some stained cytoplasm in combination with larger shape and non-spherical outline [3]. Small spherical or asymmetrical nuclei without cytoplasm but with a thicker nuclear membrane and more heterogeneous chromatin were identified as glial cells.

The spatial pattern of the surviving neurons along the gyrus was determined in laminae II/III and V/VI using spatial pattern analysis [2,4,6,7]. If neuronal perikarya are randomly distributed along the cortex, their frequency distribution will be described by a Poisson distribution and the variance/mean ratio (V/M) of their densities will be close to unity. A V/M ratio less than unity indicates a regular or uniform distribution and greater than unity - a clumped or clustered distribution. To determine the size of any possible clusters of neurons and whether the clusters were themselves randomly or regularly distributed, counts of neurons in adjacent sample fields were added together successively to provide data for increasing field sizes, e.g. $50 \times 250 \mu \mathrm{m}, 50 \times 500 \mu \mathrm{m}, 50 \times 1000 \mu \mathrm{m}$ etc., up to a size limited by the length of the strip sampled. $V / M$ is calculated at each stage and plotted against the field size. A V/M peak indicates the presence of regularly spaced clusters while an increase in $\mathrm{V} / \mathrm{M}$ to an asymptote suggests the presence of randomly distributed clusters. The field size at which the peak occurs indicates the cluster size. The significance of a V/M peak was tested using the ' $t$ ' distribution $[2,4,6,7]$. These data were also used to estimate the overall density of the surviving neurons within each gyrus.

\section{Correlation between $\operatorname{PrP}^{\mathrm{Sc}}$ deposit area and embedded neurons}

The distribution of diffuse deposits in the cortex in VCJD varies with laminar depth [11]. Hence, to investigate the correlation between the size of a diffuse PrPsc deposit and frequency of embedded neuronal perikarya, guidelines were marked on the slide extending from the pia mater to the white matter. All diffuse deposits touching a guideline were included in the sample. Florid deposits are small, symmetrical PrPsc aggregates consisting of a condensed core and easily distinguishable from diffuse deposits which are less compact and more weakly stained and lack a distinct core $[10,27]$ (Fig. 1). The diameter of each deposit was measured using a micrometer scale and the number of neuronal perikarya embedded within the deposit 
counted. For a neuron to be included in the sample, at least $75 \%$ of its cell body had to be contained within the margin of the deposit. As the majority of diffuse deposits are approximately spherical, the relationship between the deposit area, estimated from deposit radius, and number of embedded neurons was tested using correlation and regression methods. In addition, the density of neuronal perikarya embedded within diffuse deposits was estimated for each gyrus.

\section{Frequency distribution of the number of neurons within deposits}

A frequency distribution was constructed for each brain region, pooling data from all cases, of the number of deposits containing $0,1,2,3, \ldots, n$ embedded neuronal cell bodies. To determine whether these frequency distributions were random, a Poisson distribution was fitted to the data [34] using STATISTICA software (Statsoft Inc., 2300 East 14 ${ }^{\text {th }}$ St, Tulsa, Ok, 74104, USA). The Kolmogorov-Smirnov (KS) and chisquare $\left(\chi^{2}\right)$ goodness-of-fit tests were used to determine whether the frequency distributions deviated significantly from Poisson.

\section{Results}

Examples of the spatial patterns of the surviving neuronal cell bodies along the cortex in the upper laminae (II/III) in three gyri are shown in Fig. 2. In the frontal cortex, the $\mathrm{V} / \mathrm{M}$ ratio increased with field size without reaching a peak indicating the presence of large clusters of neurons, at least $1600 \mu \mathrm{m}$ in diameter, measured parallel to the pia mater. The $\mathrm{V} / \mathrm{M}$ at the smallest field size $(50 \times 250 \mu \mathrm{m})$ was close to unity indicating that within the larger clusters of neurons, individual neuronal perikarya were randomly distributed. In the occipital cortex, the V/M ratio was significantly less than unity indicating a uniform distribution of cell bodies while in the $\mathrm{PHG}$, the V/M ratio did not differ from unity at any field size suggesting a random distribution of neurons.

The densities and spatial patterns of neuronal cell bodies in the data as a whole are summarised in Table II. The density of neurons was greatest in the occipital cortex while frontal and parietal cortex and the PHG had similar but lower densities. Neurons were randomly distributed in 6/48 (12.5\%) areas studied, uniformly distributed in $23 / 48$ (48\%) areas, in regularly distributed clusters in 10/48 (21\%) areas, and in large clusters (> $1600 \mu \mathrm{m})$ in 9/48 (19\%) areas. In gyri with

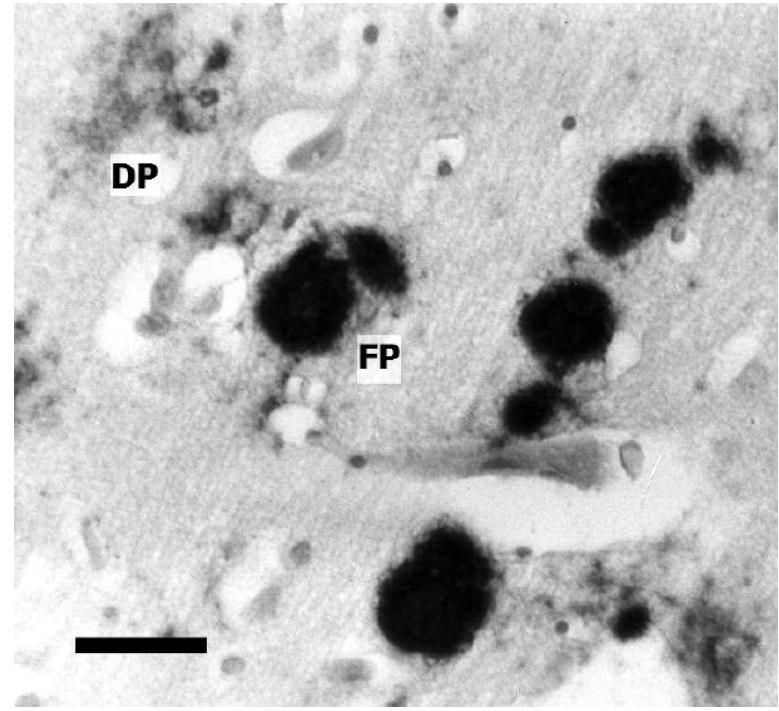

Fig. 1. Examples of diffuse (DP) and florid (FP) prion protein (PrPsc) deposits in variant Creutzfeldt-Jakob disease (vCJD) (section immunolabelled with antibody 12F10 against PrP, haematoxylin counterstain; magnification bar $=60 \mu \mathrm{m}$ ).

large-scale clustering of neurons, neurons were randomly distributed within the larger clusters.

The densities of neuronal perikarya embedded within diffuse PrPsc deposits and the correlation between deposit area and number of embedded neurons

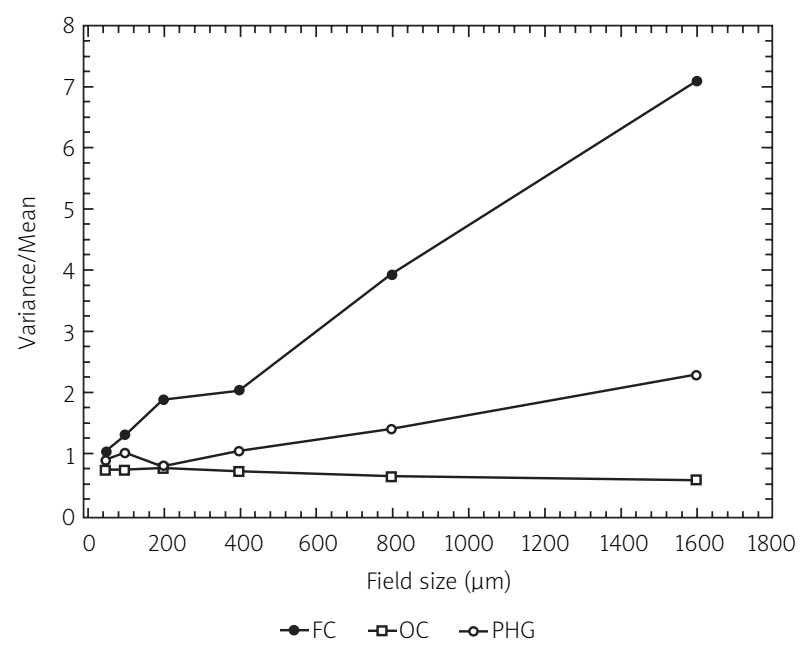

Fig. 2. Spatial pattern analysis of the surviving neurons along a strip of tissue parallel to the pia mater in three cortical gyri (FC - frontal cortex, OC - occipital cortex, PHG - parahippocampal gyrus) in variant Creutzfeldt-Jakob disease (vCJD). 
Table II. Densities (50 $\times 250 \mu \mathrm{m}$ field) and spatial patterns of the surviving neurons in various areas of the cerebral cortex of six cases of variant Creutzfeldt-Jakob disease (vCJD)

\begin{tabular}{|c|c|c|c|c|c|}
\hline \multicolumn{2}{|c|}{ Case } & \multicolumn{4}{|c|}{ Brain region } \\
\hline & & $\mathrm{FC}$ & PC & $O C$ & PHG \\
\hline \multirow[t]{2}{*}{ A } & Density & 5.74 & 8.44 & 15.49 & 5.92 \\
\hline & Spatial pattern & $>1600,400$ & Rg, R & Rg, 800 & 800,800 \\
\hline \multirow[t]{2}{*}{ B } & Density & 8.48 & 8.74 & 12.62 & 9.13 \\
\hline & Spatial pattern & $\mathrm{R}, \mathrm{Rg}$ & Rg, 400 & Rg, 800 & 800,800 \\
\hline \multirow[t]{2}{*}{$C$} & Density & 7.02 & 10.33 & 17.95 & 5.58 \\
\hline & Spatial pattern & $>1600,100$ & $>1600,800$ & $>1600,>1600$ & $R, R$ \\
\hline \multirow[t]{2}{*}{$\mathrm{D}$} & Density & 5.76 & 7.67 & 13.86 & 7.62 \\
\hline & Spatial pattern & $\mathrm{Rg}, \mathrm{Rg}$ & $>1600, \operatorname{Rg}$ & Rg, 800 & $\mathrm{Rg}, \mathrm{Rg}$ \\
\hline \multirow[t]{2}{*}{$\mathrm{E}$} & Density & 8.33 & 5.40 & 16.60 & 5.58 \\
\hline & Spatial pattern & $\mathrm{Rg}, \mathrm{Rg}$ & $>1600, \mathrm{Rg}$ & $>1600,800$ & $\mathrm{Rg}, \mathrm{Rg}$ \\
\hline \multirow[t]{2}{*}{$F$} & Density & 4.96 & 7.69 & 14.61 & 8.88 \\
\hline & Spatial pattern & $\mathrm{Rg}, \mathrm{Rg}$ & $800,>1600$ & $\mathrm{Rg}, \mathrm{Rg}$ & $\mathrm{Rg}, \mathrm{Rg}$ \\
\hline
\end{tabular}

$F C$ - frontal cortex, $P C$ - parietal cortex, OC - occipital cortex, PHG - parahippocampal gyrus

Figures for spatial patterns are the estimated sizes of clusters $(\mu \mathrm{m})$ except $R$ (random distribution) and $R g$ (regular distribution), the first entry is spatial pattern along laminae II/III and the second along laminae V/VI

Table III. Densities of neuronal cell bodies embedded within diffuse prion protein PrPsc deposits and the correlation (Pearson's ' $r$ ') between deposit area and number of embedded neurons in different cortical areas of six cases of variant Creutzfeldt-Jakob disease (VCJD) $\left(N-\right.$ number of deposits, ${ }^{*} P<0.05,{ }^{* *} P<0.01$, $\left.{ }^{* * *} P<0.001\right)$

\begin{tabular}{|lccccc|}
\hline Region & $N$ & $\begin{array}{c}\text { Mean area } \\
\text { of deposit }\end{array}$ & $\begin{array}{c}\text { Mean number } \\
\text { of embedded } \\
\text { neurons }\end{array}$ & $\begin{array}{c}\text { Expected density } \\
\text { of neurons }\end{array}$ \\
\hline Frontal cortex & 154 & 538.97 & 1.92 & 0.30 & $0.18^{\star}$ \\
\hline Parietal cortex & 147 & 578.35 & 1.89 & $0.32^{* * *}$ \\
\hline Occipital cortex & 132 & 693.47 & 3.04 & $0.41^{* * *}$ & 0.21 \\
\hline Parahippocampal gyrus & 133 & 363.29 & 1.76 & $0.23^{* *}$ \\
\hline
\end{tabular}

is shown in Table III. Densities of neurons within diffuse PrPsc deposits were three to eight times greater than the estimated overall density in the tissue. The relationship between deposit area and the number of embedded neurons in shown for a single gyrus (occipital cortex) in Fig. 3. The deposit area and number of embedded neurons were positively correlated $(r=0.41, P<0.001)$, a relationship present in all of the gyri studied.
The frequency distribution of the diffuse PrPsc deposits containing $0,1,2,3, \ldots, n$, embedded neuronal perikarya is shown in Fig. 4 and the goodness of fit to the Poisson distribution for each brain region in Table IV. None of the frequency distributions departed significantly from a Poisson distribution (KS $=0.028-0.064$, $P>0.05)$ suggesting that the frequency distribution of the number of neurons embedded within diffuse deposits was essentially random. 


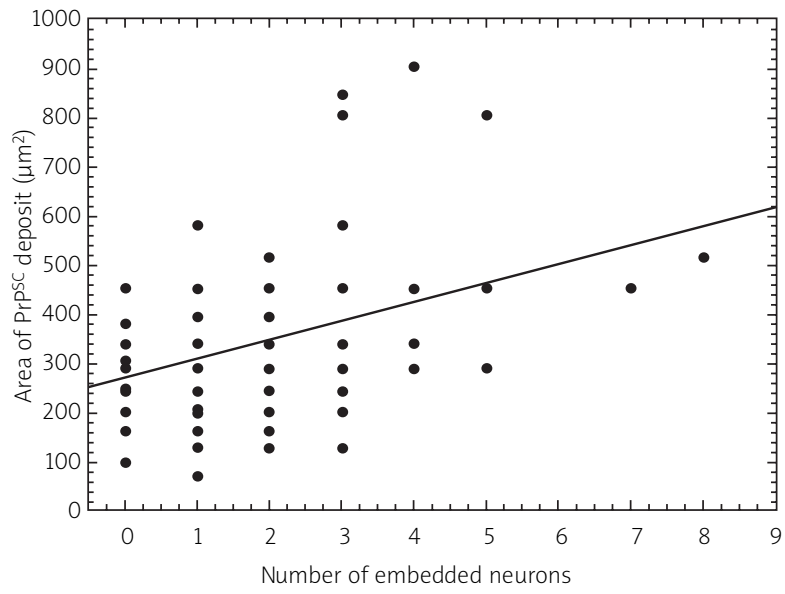

Fig. 3. Correlation between the area of diffuse prion protein (PrPsc) deposits and the number of embedded neurons in the occipital cortex in variant Creutzfeldt-Jakob disease (vCJD).

\section{Discussion}

In approximately $50 \%$ of gyri studied, surviving neurons were uniformly distributed along the cortex, a spatial pattern also present in cognitively normal brain [13]. This result suggests that neuronal losses are likely to have occurred relatively evenly along the cortex. In a smaller number of gyri, surviving neurons exhibited a degree of clustering, and in some gyri the clusters were regularly distributed parallel to the pia mater suggesting an alternating pattern of higher and lower density of neurons and therefore, a more localised pattern of neuronal loss. Where large clusters of neurons were present, neuronal perikarya were usually randomly or uniformly distributed within those clusters.

A comparison of neurons embedded within diffuse PrPsc deposits with those of the gyrus as a whole suggests that diffuse deposits contain three to eight times more embedded neurons per unit of area than would be expected from their overall density in the section. These data suggest that diffuse deposits develop as a result of the formation of $\mathrm{PrPsc}$ in relation to clusters of neuronal perikarya. Hence, this process may be similar to that of the formation of diffuse $\beta$-amyloid (A $\beta$ ) deposits observed in Alzheimer's disease (AD) $[5,9]$. In both $A D$ and Down's syndrome (DS), diffuse $A \beta$ deposits are closely associated with the presence of neuronal cell bodies and may have developed from $A \beta$ secreted from clusters of adjacent neurons [1,3,8,32].

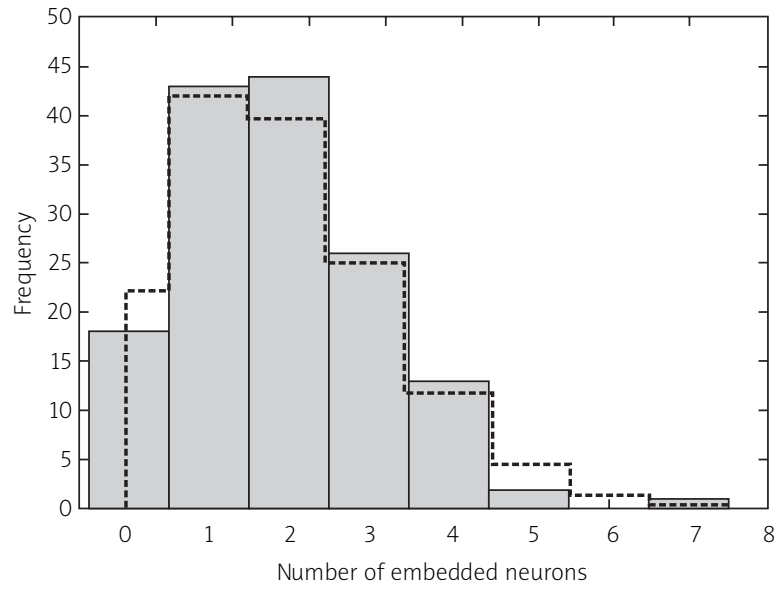

Fig. 4. Frequency distribution of diffuse prion protein (PrPsc) deposits that contain 0, 1, 2, 3, ..., n embedded neurons. Dashed histogram indicates the expected numbers based on the Poisson distribution.

In each cortical region studied, there was a positive correlation between PrPsc deposit area and the number of embedded neurons. A number of processes could account for this correlation. First, soluble PrPc could be secreted from a single source such as a cell process, neuronal perikaryon, or glial cell, and then diffuse through the neuropil and engulf neuronal perikarya before being converted into PrPsc [9]. The number of neurons embedded within a diffuse deposit would then depend on the amount of $\operatorname{PrP}^{\mathrm{c}}$ secreted and the area over which diffusion occurred. Increased density of cell bodies embedded within diffuse deposits, however, would argue against this hypothesis since diffusion of $\mathrm{PrPc}^{\mathrm{C}}$ should engulf neurons regardless of their degree

Table IV. Frequency distributions of diffuse prion protein (PrPsc) deposits that contain $0,1,2,3, \ldots$, $n$ embedded neuronal perikarya in different cortical areas of six cases of variant CreutzfeldtJakob disease (vCJD): Goodness-of-fit to a Poisson model $(\lambda$ - mean density, DF - degrees of freedom, KS - Kolmogorov-Smirnov statistic)

\begin{tabular}{|lccc|}
\hline Region & $\lambda$ & Chi-square $\left(\chi^{2}\right)$ & KS \\
\hline Frontal cortex & 1.92 & 8.33 (4DF) $P>0.05$ & $0.064, P>0.05$ \\
\hline Parietal cortex & 1.89 & 3.23 (4DF) $P>0.05$ & $0.028, P>0.05$ \\
\hline Occipital cortex & 3.04 & 5.80 (5DF) $P>0.05$ & $0.040, P>0.05$ \\
\hline $\begin{array}{l}\text { Parahippocampal } \\
\text { gyrus }\end{array}$ & 1.75 (3DF) $P>0.05$ & $0.031, P>0.05$ \\
\hline
\end{tabular}


of clustering. Second, the formation of a diffuse deposit could alter the spatial relationship between adjacent cell bodies, e.g. PrPsc developing in relation to two closely adjacent neurons might draw the cell bodies even closer together increasing their density. However, there is no evidence that the distance between neurons was less in deposits heavily immunolabelled compared with those more lightly labelled. Third, molecular 'chaperones' diffusing within the neuropil [12,37] might cause the developing deposit to condense thus reducing the distance between neurons. Although there is evidence that the florid PrPsc deposits may result from condensation of PrPsc [12] this is less likely to be true in diffuse deposits. Fourth, neurons may be lost at greater rates between than within deposits. However, the regular or random distribution of neurons along the cortex in a significant number of gyri would argue against this hypothesis. Hence, the most plausible explanation consistent with the data is that the size of a diffuse deposit is determined by the number of adjacent neurons in which PrPsc is formed.

The mechanism by which PrPsc accumulation may cause neurodegeneration is poorly understood [14] but, in cultured neurons, addition of PrPsc alters cell membranes, increases cholesterol, activates cytoplasmic phospholipase A2, and triggers synapse damage. The present data suggest that the frequency distribution of the number of embedded neurons within diffuse deposits did not deviate significantly from a Poisson distribution. Hence, the formation of PrPsc appears to occur independently within each neuron, i.e. formation in one neuron does not increase the probability that an adjacent neuron will also be affected. Hence, it is unlikely that PrPsc formation in one neuron has a direct pathological effect on its neighbour. The Poisson distribution also predicts that the probability that 3 or more adjacent neurons will simultaneously contribute PrPsc to form a diffuse deposit decreases markedly, thus restricting the ultimate size of such deposits in the brain.

In conclusion, the data suggest that diffuse PrPsc deposits in VCJD may develop as a result of the formation of PrPsc in association with local clusters of neurons, the size of a deposit being determined by the number of adjacent neurons involved. The probability that an individual neuron develops PrPsc appears to be independent of that of its immediate neighbours. The probability that 3 or more neurons develop PrPsc and form a deposit decreases markedly thus restrict- ing the size to which diffuse deposits will grow. These results may also explain the positively skewed size frequency distributions of diffuse deposits commonly observed in VCJD [12].

\section{Acknowledgements}

The assistance of the CJD Surveillance Unit in providing cases for this study and the Brain Bank, Institute of Psychiatry, King's College London for preparing the tissue sections is gratefully acknowledged.

\section{References}

1. Allsop D, Haga S, Ikeda SI, Mann DMA, Ishii T. Early senile deposits in Down's syndrome brains show a close relationship with cell bodies of neurons. Neuropathol Appl Neurobiol 1989; 15: 531-542.

2. Armstrong RA. The usefulness of spatial pattern analysis in understanding the pathogenesis of neurodegenerative disorders with particular reference to deposit formation in Alzheimer's disease. Neurodegeneration 1993; 2: 73-80.

3. Armstrong RA. Correlations between the morphology of diffuse and primitive $\beta$-amyloid (A $\beta$ ) deposits and the frequency of associated cells in Down's syndrome. Neuropath Appl Neurobiol 1996; 22: 527-530.

4. Armstrong RA. Analysis of spatial patterns in histological sections of brain tissue. J Neurosci Meth 1997; 73: 141-147.

5. Armstrong RA. Diffuse $\beta$-amyloid $(A \beta)$ deposits and neurons: in situ secretion or diffusion of A $\beta$. Alz Rep 2001; 3: 289-294.

6. Armstrong RA. Methods of studying the planar distribution of objects in histological sections of brain tissue. J Microsc 2006; 221 : 153-158.

7. Armstrong RA. Measuring the spatial arrangement patterns of pathological lesions in histological sections of brain tissue. Folia Neuropathol 2006; 44: 229-237.

8. Armstrong RA. Cairns NJ, Lantos PL. Degeneration of cortical neurons associated with diffuse $\beta$-amyloid $(A \beta)$ deposits in Alzheimer's disease. Neurosci Res Commun 1999; 24: 89-97.

9. Armstrong RA, Cairns NJ, Lantos PL The spatial patterns of prion protein deposits in Creutzfeldt-Jakob disease: comparison with $\beta$-amyloid deposits in Alzheimer's disease. Neurosci Lett 2001; 298: 53-56.

10. Armstrong RA, Lantos PL, Ironside JW, Cairns NJ. Differences in the density and spatial distribution of florid and diffuse deposits in variant Creutzfeldt-Jakob disease (vCJD). Clin Neuropath 2003; 22: 209-214.

11. Armstrong RA, Cairns NJ, Ironside JW, Lantos PL. Laminar distribution of the pathological changes in the cerebral cortex in variant Creutzfeldt-Jakob disease (vCJD). Folia Neuropathol 2003; 40: 165-171.

12. Armstrong RA, Cairns NJ, Ironside JW, Lantos PL. Size frequency distribution of prion protein (PrP) aggregates in variant CreutzfeldtJakob disease (vCJD). J Neural Transm 2005; 112: 1565-1573.

13. Armstrong RA, Cairns NJ, Lantos PL. Multiple system atrophy (MSA): Topographic distribution of the $\alpha$-synuclein-associated pathological changes. Parkinsonism and Rel Disord 2006; 12: 356-362. 
14. Bate C, Williams A. Neurodegeneration induced by clustering of sialylated glycosylphosphatidylinositols of prion proteins. J Biol Chem 2012; 287: 7935-7944.

15. Fournier JG, Kopp N, Streichenberger N, Escaig-Haye F, Langeveldt J, Brown P. Electron microscopy of brain amyloid deposits from a patient with new variant Creutzfeldt-Jakob disease. Acta Neuropathol 2000; 99: 637-642.

16. Gomes MPB, Vieira TCRG, Cordeiro Y, Silva JL. The role of RNA in mammalian prion protein conversion. Wiley Interdisc Rev 2012; 3: $415-428$.

17. Hara H, Okemoto-Nakamura Y, Shinkai-Ouchi F, Hanada K, Yamakawa Y, Hagiwara K. Mouse prion protein (PrP) segment 100 to 104 regulates conversion of PrPC to PrPSC in prion infected neuroblastoma cells. J Virol 2012; 86: 5626-5636.

18. Hill AF, Butterworth RJ, Joiner S, Jackson G, Rossor MN, Thomas DJ, Frosh A, Tolley N, Bell JE, Spencer M, King A, Al-Sarraj S, Ironside JW, Lantos PL, Collinge, J. Investigation of variant Creutzfeldt-Jakob disease and other human prion diseases with tonsil biopsy samples. Lancet 1999; 353: 183-189.

19. Ironside JW. Pathology of variant Creutzfeldt-Jakob disease. Arch Virol (Suppl) 2000; 16: 143-151.

20. Ironside JW, Sutherland K, Bell JE, McCardle L, Barrie C, Estebeiro K, Zeidler M, Will RG. A new variant Creutzfeldt-Jakob disease: Neuropathological and clinical features. Cold Spring Harbor Symp Quant Biol 1996; 61: 523-530.

21. Ironside JW, Head MW, Bell JE, McCardle L, Will RG. Laboratory diagnosis of variant Creutzfeldt-Jakob disease. Histopathology 2000; 37: 1-9.

22. Ironside JW. Variant Creutzfeldt-Jakob disease: an update. Folia Neuropathol 2012; 50: 50-56

23. Jeffrey M, McGovern,. G, Chambers EV, King D, Gonzalez L, Manson JC, Ghetto B, Piccardo P, Barron RM. Mechanism of PrP-amyloid formation in mice without transmissible spongiform encephalopathy. Brain Pathol 2012; 22: 58-66.

24. Krasemann S, Groschup MH, Harmeyer S, Hunsman G, Bodemer W. Generation of monoclonal antibodies against human prion proteins in PrPO/O mice. Mole Med 1996; 2: 725-734.

25. Kundu B, Maiti NR, Jones EM, Surewicz KA, Vanik DL, Surewicz WK. Nucleation-dependent conformational conversion of the Y145Stop variant of human prion protein: Structural clues for prion propagation. Proc Nat Acad Sci USA 2003, 100, 12069-12074.

26. Li GY, Zhou P, Shao ZZ, Xie X, Chen X, Wang HH, Chunyu LJ, Yu TY. The natural silk spinning process: A nucleation-dependent aggregation mechanism. Eur J Biochem 2001; 268: 6600-6606.

27. Liberski PP, Ironside JW, McCardle L, Shering A. Ultrastructure analysis of the florid deposit in variant Creutzfeldt-Jakob disease. Folia Neuropathol 2000; 38: 167-170.

28. Liberski PP. Historical overview of prion diseases: a view from afar. Folia Neuropathol 2012; 50: 1-12.

29. Marandi Y, Farahi N, Sadeghi-Hashjin G. Prion disease - current theories and potential therapies: a brief review. Folia Neuropathol 2012; 50: 46-49.

30. Martin R, Chantepie S, Chapuis J, Le-Duc A, Maftah A, Papy-Garcia D, Laude H, Petit JM, Gallet PF. Variation in Chst8 gene expres sion level affects PrPC to PrPSc conversion efficiency in prioninfected Mov cells. Biochem Biophys Res 2011; 414: 587-591.
31. McLean CA, Ironside JW, Alpers MP, Brown PW, Cervenakova LR, Anderson R, Masters CL. Comparative neuropathology of kuru with new variant Creutzfeldt-Jakob disease: evidence for strain of agent predominating over genotype of host. Brain Pathol 1998; 8: 429-437.

32. Mochizuki A, Peterson JW, Mufson EJ, Trapp BD. Amyloid load and neural elements in Alzheimer's disease and nondemented individuals with high amyloid deposit density. Exp Neurol 1996; 142: 89-102.

33. Peters PJ, Mironov A, Perezz D, van Douselaar E, LeClerc E, Erpel S, deArmond J, Burton DR, Willaimson RA, Vey M, Prusiner SB. Trafficking of prion proteins through a caveolae-mediated endosomal pathway. J Cell Biol 2003; 162: 703-714.

34. Pollard JH. Numerical and Statistical Techniques. Cambridge University Press, Cambridge 1979.

35. Stanley HE, Buldyrev SV, Cruz L, Gomez-Isla T, Havlin S, Hyman BT, Knowles R, Urbanc B, Wyart C. Statistical physics and Alzheimer's disease. Physica A 1998; 249: 460-471.

36. Turnbaugh JA, Unterberger U, Saa P, Massignan T, Fluharty BR, Bowman FP, Miller MB, Supattapone S, Biasini E, Harris DA. The N-terminal polybasic region of PrPC dictates the efficiency of prion propagation by binding to PrPSC. J Neurosci 2012; 32: 8817-8830.

37. Urbanc B, Cruz L, Buldyrev SV, Havlen S, Irizarry MC, Stanley HE, Hyman BT. Dynamics of deposit formation in Alzheimer's disease. Biophys J 1999; 76: 1330-1334.

38. Vila-Vicosa D, Campos SRR, Baptista AM, Machuqueiro M. Reversibility of prion misfolding: insights from constant-pH molecular dynamics simulations. J Phys Chem 2012; 116: 8812-8821.

39. Will RG, Ironside JW, Zeidler M, Cousens SN, Estibeiro K, Alperovitch A, Poser S, Pocchiari M. Hofman A, Smith PG. A new variant of Creutzfeldt-Jakob disease in the United Kingdom. Lancet 1996; 347: 921-925.

40. Younan ND, Nadal RC, Davies P, Brown DR, Viles JH. Methionine oxidation perturbs the structural core of the prion protein and suggests a generic misfolding pathway. J Biol Chem 2012; 287: 2826328275. 